Submission ID: 43802

\title{
Elaboration of Lithofacies Characteristic of Terrigenous Deposits of Devonian in the Platform Area of the Republic of Bashkortostan
}

A.A. Gubaydullina* (BashNIPIneft LLC ), A.S. Dushin (BashNIPIneft LLC), R.F. Sharipov (BashNIPIneft LLC)

\section{SUMMARY}

The tasks of the research included detailed description of the core with further distinguishing of lithotypes, examination of geological aspects, generation of lithologic and facies maps. In the work the facies model of Devonian terrigenous stratum isformed; the model was obtained based on description of the core of 30 wells, analyses of 423 thin sections and granulometry data of 440 samples. The basis to distinguish lithotypes is layer-by-layer description of rocks according to lithological composition and fraction size as per granulometry, as well as peculiar textural features. In the result of performed analysis of the deposit core of Devonian terrigenous stratum there are 14 lithotypes, which served as a basis for transition to deposition environment and further distinguishing of facies. To specify depositional conditions regional data were used according to which deposition of sediments in the period of formation of Devonian terrigenous stratum took place in conditions of shallow sea.According to comprehensive study data of the core and geophysical well logging, in the sections of the key-wells relevant facies were distinguished and facies inhomogeneity maps were generated (from the point of view of cyclic structure of horizons). 


\section{Уточнение литолого-фациальной характеристики терригенных отложений девона платформенной части Республики Башкортостан}

А.А.Губайдуллина * (ООО «БашНИПИнефть»), А.С. Душин (ООО «БашНИПИнефть»), Р.Ф. Шарипов (ООО «БашНИПИнефть»)

\section{Введение}

Терригенная толща девона платформенной части республики Башкортостан долгое время оставалась основным комплексом для нефтедобычи в республике, и, несомненно, изучена достаточно подробно. Однако даже при такой высокой изученности, на сегодняшний день остаются краевые участки структур и разведочные площади, слабо охваченные поисковым и разведочным бурением, которые могут представлять интерес для изучения.

Цель работы заключалась в создании фациальной модели терригенной толщи девона платформенной части республики Башкортостан. В задачи исследования входило детальное описание керна с последующим выделением литотипов, изучение особенностей геологического строения, построение литолого-фациальных карт. В работе формулируется фациальная модель отложений ТТД, полученная по описанию керна по 30 скважинам (рисунок 1), анализам 423 шлифов и данных гранулометрии 440 образцов.

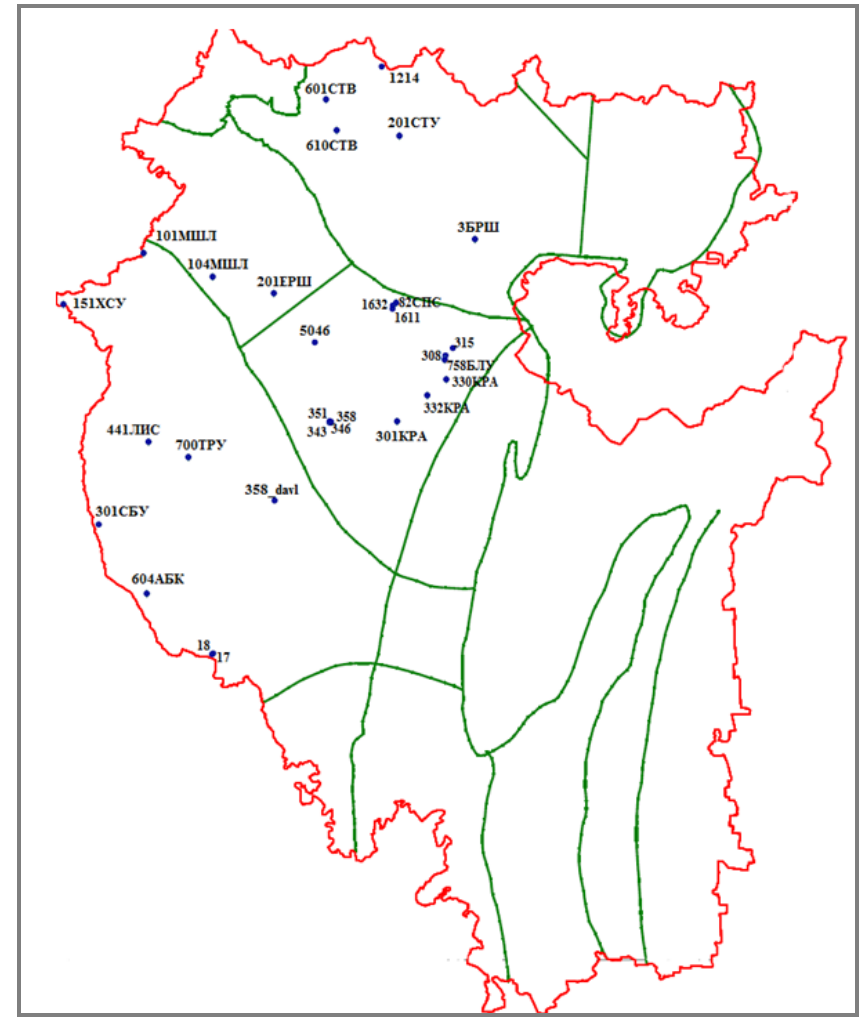

Рисунок 1 Карта расположения скважин с керном

\section{Методы}

Основой выделения литотипов является послойное описание пород по литологическому составу и размеру фракции по гранулометрии (песчаники, алевролиты, аргиллиты и глинистокарбонатная порода), а также присущие им текстурные признаки. Данные гранулометрического состава образцов были использованы для уточнения литологического состава выделенных литотипов, определенного при макро- и микроописании керна. Разделение фракций при гранулометрическом анализе осуществлено по десятичной схеме классификации обломочных пород, границы выделения фракций следующие: песчаная 0,1-1 мм, алевритовая 
0,01-0,1 мм, глинистая <0,01 мм. Описания шлифов дополнили выделенные литотипы информацией о типе, составе и количестве цемента, степени сортировки зерен, включении минеральных составляющих. В результате выполненного анализа по керну отложений ТТД выделяются 14 литотипов. Наиболее широко распространенными являются литотипы: горизонтально-слоистый алевролит, массивный песчаник, алевролит с волнистой слоистостью, аргиллит и алевролиты с биотурбационной текстурой (рисунок 2) Выделенные литотипы говорят о том, что осадконакопление происходило как в областях с низкой энергией, так и в зонах активно перерабатываемых приливно-отливной деятельностью и организмамибиотурбаторами. В исследуемом регионе наряду с терригенной, присутствует и карбонатная седиментация, об этом свидетельствуют карбонатные реперы, которые прослеживаются почти во всех горизонтах, в них выделяется литотип глинисто-карбонатная порода.

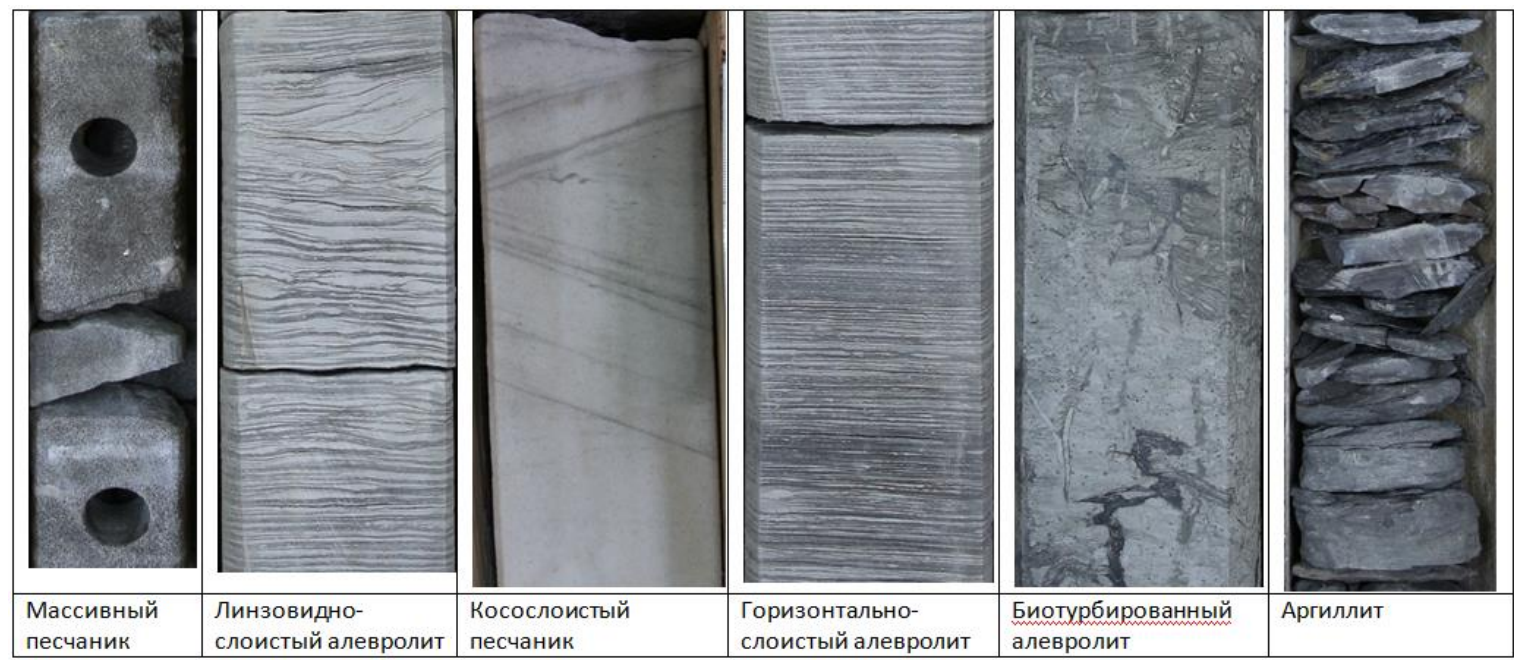

Рисунок 2 Преобладающие литотипь отложений ТТД

Основой для перехода к обстановкам осадконакопления и дальнейшего выделения фаций послужили выделенные текстурные признаки в изучаемых отложениях, характеризующие геологические условия образования.

Для уточнения условий седиментации были привлечены региональные данные, согласно которым осадконакопление в период формирования ТТД происходило в условиях мелкого моря [1]. Осадконакопление в период формирования толщи терригенного девона происходило в регрессивно-трансгрессивном режиме. Обмелевшее море то отступало, то надвигалось, но, в общем, оставался режим мелких заливов с активным осадконакоплением. Снос материала происходил с севера, северо-востока и востока [2]. Изучаемая толща имеет циклическое строение, обусловленное трансгрессивно-регрессивным режимом бассейна и состоящим из чередования глинистых, карбонатных прослоев и песчано-алевролитовых прослоев с улучшенными коллекторскими свойствами. Проведенный послойный анализ керновых данных позволил отнести рассматриваемые отложения к прибрежно-морским с преобладанием приливно-отливной деятельности. В разрезах опорных скважин по комплексному анализу данных керна и ГИС были выделены соответствующие фации: активный канал приливноотливной протоки, приливно-отливная отмель, отложения низких маршей, временно заливаемые морем, прибрежные бары, морские карбонатные отложения относительного глубоководья и шельфовые аргиллиты.

С целью пространственного картирования выделенных фаций исследуемой территории, к скважинам с керном были привлечены скважины с комплексом ГИС. Выделение фаций в таких скважинах без отбора керна проводилось на основе нормированных каротажных кривых. За основу принимался электрофациальный анализ формы кривой гамма-каротажа (ГК) и нейтронного гамма-каротажа (НГК). В построении карт участвовало около 200 скважин. При этом для локального уточнения зон требуется более детальное рассмотрение с подключением в анализ большего количества скважин. Фациальная характеристика дается по продуктивным горизонтам наиболее полно охваченным керновым материалом, с учетом выделенной 
внутрипластовой цикличности: ардатовскому (включающему циклиты D2ar1, D2ar2), муллинскому (включающему циклиты $\mathrm{D} 2 \mathrm{ml} 1, \mathrm{D} 2 \mathrm{ml} 2$ ), пашийскому (включающему циклиты $\mathrm{D} 2 \mathrm{ps} 1, \mathrm{D} 2 \mathrm{ps} 2$ ) и тиманскому (включающему циклиты D3tm1, D3tm2, D3tm3). Фациальные карты построены с точки зрения цикличности строения горизонтов (рисунок 3). Выделенные фациальные зоны согласуются с региональными данными о расположении источников сноса и направлении развития трансгрессии. В связи с общим наклоном территории в сторону Прикаспийской синеклизы отмечается смена фаций с юга на север от глубокой части шельфа к верхней части и затем к прибрежно-морским образованиям.
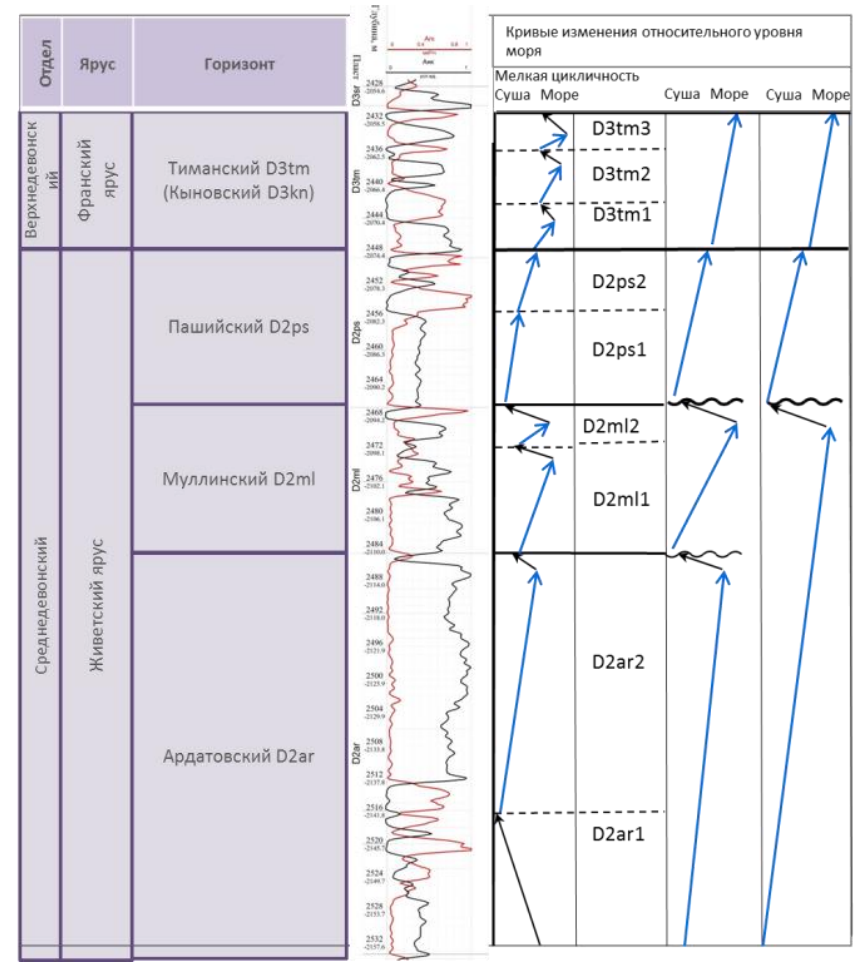

Рисунок 3 Пример колонки скважины с выделенными мелкими ијиклами, соответствующие самостоятельным эпизодам осадконакопления

На территории исследования этапу регрессии соответствуют фации с формированием песчаноалевритовых пород с улучшенными коллекторскими свойствами, в частности это песчаные пласты фаций активных каналов, к которым приурочены залежи нефти в ТТД, и пересекаемые ими фации приливно-отливной отмели с аргиллит-алевролитовыми породами. Фации низких маршей и прибрежных баров имеют подчиненное значение и выделяются в небольшие по площади зоны. Трансгрессивный этап осадконакопления характеризуется карбонатноглинистыми осадками зон карбонатной сублиторали и шельфовых аргиллитов, что соответствует распространению карбонатных реперов и глинистых толщ, выполняющих роль флюидоупоров. Предыдущими исследователями были получены схематические литологофациальные карты, на которых выделялись зоны по преобладанию содержания пород по литологическому составу [3]. В данной работе получены карты именно фациальной неоднородности, которые отражают накопление этих пород в определенной фациальной обстановке.

\section{Выводы}

В результате работы построены карты фациальной неоднородности для каждого цикла, что дает возможность проследить распределение по площади и разрезу месторождений типов фаций, отличающихся своими фильтрационно-емкостными свойствами (рисунок 4). Это позволяет прогнозировать развитие коллекторских свойств и определять краевые и малоисследованные участки для постановки геолого-разведочных работ. Данная работа 


\section{EAGE}

позволила уточнить литолого-фациальные схемы, построенные по принципу преобладания пород по литологическому составу, и перейти на обстановки осадконакопления с отражением фациальной неоднородности по площади.

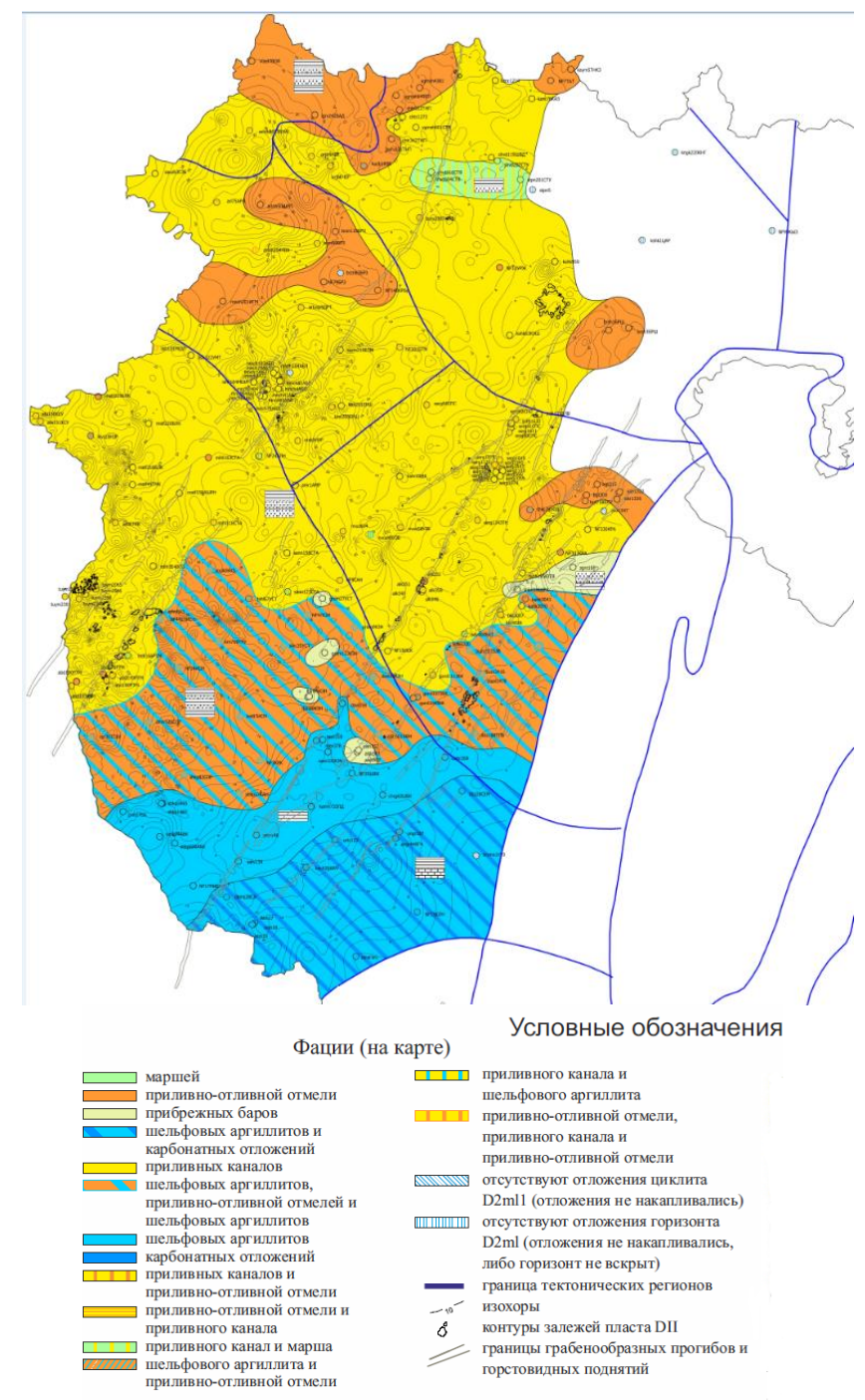

Рисунок 4 Пример карты фащиальной неоднородности для отложений муллинского горизонта $D 2 m 1$

\section{Библиография}

1. Алиев М. М., Батанова Г. П., Хачатрян Р. О. и др. Девонские отложения ВолгоУральской нефтегазоносной провинции - Москва: Недра, 1978. - 216 с.

2. Лозин Е. В. Геология и нефтеносность Башкортостана - Уфа: БашНИПИнефть, 2015. $704 \mathrm{c}$.

3. Тюрихин А.М., Юнусов М.А., Масагутов Р.Х., Лозин Е.В. Строение и эволюция осадочного чехла платформенной Башкирии в связи с закономерностями размещения залежей нефти и газа. Отчет по договору № 9-03/991 (0185) БашНИПИнефть - Уфа, 1989. - 338 с. 


\section{References}

1. Aliev M.M., Batanova G. P., Khachatryan R. O. i dr. Devonskie otlozheniya Volgo-Uralskoi neftegazonosnoi provincii - Moskva: Nedra, 1978. - $216 \mathrm{~s}$.

2. Lozin E. V. Geologiya i neftenosnost Bashkortostana - Ufa:BashNIPIneft, 2015. - $704 \mathrm{~s}$.

3. Tyurihin A. M., Yunusov M. A., Masagutov R. H., Lozin E. V. Stroenie i evolyuciya osadochnogo chehla platformennoi Bashkirii v svyazi s zakonomernostyami razmecheniya zalezhei nefti i gaza. Otchet po dogovoru №9-03/991 (0185) BashNIPIneft - Ufa, 1989. $338 \mathrm{~s}$. 